\title{
O Novo Capitalismo Pós-Segunda Guerra Mundial: Entre o Liberalismo e o Neoliberalismo
}

\author{
Luciana Borella Camara Ardenghi \\ Mestre em Direitos Humanos pela Universidade Regional \\ do Noroeste do Estado do Rio Grande do Sul - Unijuí e \\ professora da Universidade Regional Integrada do Alto \\ Uruguai e das Missões - URI Frederico Westphalen. \\ camara@uri.edu.br.
}

\section{Queli Cristiane Schiefelbein da Silva}

Mestre em Direitos Humanos pela Universidade Regional do Noroeste do Estado do Rio Grande do Sul - Unijuí; especialista em Ciências Penais pela Universidade do Sul de Santa Catarina - Unisul e Técnica Judiciária da Justiça Federal, onde exerce a função de Supervisora da Unidade Avançada de Atendimento da Justiça Federal em ljuí/RS. quelicss@yahoo.com.br.

\section{Tatiane Kessler Burmann}

Mestre em Direitos Humanos pela Universidade Regional do Noroeste do Estado do Rio Grande do Sul - Unijuí; procuradora do município de ljuí/RS. tati_burmann@ hotmail.com.

\section{Resumo}

Os impactos da globalização redirecionam o Estado contemporâneo e os interesses das elites dominantes confiando-Ihes, ao contrário do que ocorria no Estado moderno, perspectivas não territoriais e extranacionais. Variáveis externas, como a maior mobilidade do capital e de políticas macroeconômicas, condicionam o Estado a reformular sua função. A perda por parte do Estado do monopólio da esfera pública, juntamente com o declínio da identidade política, reforça a necessidade de se criar uma alternativa de caráter normativo - uma regulação do mercado global e a constituição de uma esfera pública transnacional. A tendência, ao que parece e num futuro não tão distante, é transformar a cidadania nacional, surgida com os Estados territoriais modernos, em forças sociais transnacionais, acompanhando a nova ordem econômica mundial. Ou seja, a globalização interfere no sistema produtivo e financeiro mundialmente, enfraquece o poder de controle e intervenção dos Estados sobre 
os fluxos internacionais, fazendo-se necessária uma reformulação da democracia mediante criação de espaços sociais e de instituições permanentes de expressão política que transformem o cidadão passivo, caracterizador do capitalismo, em um cidadão ativo e participativo, portador de direitos e deveres. Diante desse cenário, a partir de revisões bibliográficas, abordar-se-á a evolução do novo capitalismo pós-Segunda Guerra Mundial, do liberalismo ao neoliberalismo, no intuito de demonstrar a influência da economia na democracia nacional com a globalização das relações macroeconômicas.

Palavras-chave: Capitalismo. Democracia. Globalização. Liberalismo.

\title{
The New Capitalism Post-World War II: between liberalism and neoliberalism
}

\begin{abstract}
The impacts of globalization redirect the contemporary state and the interests of the ruling elites trusting them, contrary to what happened in the modern state, territorial and perspectives not extranational. External variables, such as increased mobility of capital and macroeconomic policies influence the state to revamp its function. The loss by the state monopoly of the public sphere, along with the decline of political identity, reinforces the need to create an alternative normative character - a global market regulation and the creation of a transnational public sphere. The trend, it seems, and in a not so distant future, is to transform national citizenship, which emerged with the modern territorial states in transnational social forces, following the new world economic order. In other words, globalization affects the world financial and productive system, weakens the power of control and intervention of States over international flows, making necessary a reformulation of democracy by creating social spaces and permanent institutions of political expression that transform the citizen passive characterization of capitalism, in an active and participatory citizens, with rights and duties. Given this scenario, from literature review, will address the evolution of the new capitalism post-World War II liberalism to neoliberalism in order to demonstrate the influence of the economy on national democracy with the globalization of macroeconomic relationships.
\end{abstract}

Keywords: Capitalism. Democracy. Globalization. Liberalism.

\section{Sumário}

1 Introdução. 2 A Segunda Guerra Mundial: entre nacionalização e investimento externo. 3 0s fundamentos democráticos pós-Segunda Guerra Mundial: entre regulação econômica e democracia. 4 Globalização: economia, direito e democracia. 5 Considerações Finais. 6 Referências. 


\section{INTRODUÇÃO}

O presente artigo tem como objetivo, a partir da leitura de alguns autores, recompor um conjunto mínimo de conhecimentos comuns a respeito do capitalismo, mais precisamente, do momento entre o liberalismo e o neoliberalismo. Aborda, sem a intenção de esgotar, a base dos fenômenos globalização, desnacionalização e democracia.

Para tanto, em um primeiro momento, trata da nova ordem econômica mundial nascida com a Segunda Guerra Mundial, marcada pela (des) nacionalização e por investimento externo. $\mathrm{O}$ alto grau desse investimento abalou a soberania interna e enfraqueceu o poder regulador estatal, resultando na desnacionalização.

Na sequência, analisa os fundamentos democráticos pós-Segunda Grande Guerra, da regulação econômica à democracia. Tem-se o crescimento econômico ocorrido após essa guerra abalizado em uma política não intervencionista, caracterizada pela livre concorrência e pelo predomínio das leis de mercado e também, o início de uma fase de retomada da intervenção do Estado nas relações econômicas e uma nova perspectiva de democracia presente diante do neoliberalismo.

Por fim, traça alguns aspectos relativos à globalização, instituída com o neoliberalismo, e sua influência na economia, no Direito e na democracia do Estado. Em outras palavras, examina o novo paradigma decorrente do fenômeno da globalização, em que o local abre espaço para o global, ocasionando um entrelaçamento direto entre Estados-Nações.

\section{A SEGUNDA GUERRA MUNDIAL: Entre Nacionalização e Investimento Externo}

A Segunda Guerra Mundial, ocorrida entre 1939 e 1945, sem dúvida mudou o cenário da economia, em especial no que diz respeito à expansão do capital estrangeiro, uma vez que durante tal conflito as estruturas 
econômicas tornaram-se os principais alvos militares. O Estado teve de intervir diretamente na distribuição dos alimentos, bem como no controle da utilização da mão de obra e dos recursos disponíveis, enfim, na produção - fato esse que foi denominado por alguns autores de planificação econômica de guerra (comunismo de guerra) (Nunes, 2011).

Ressalta-se que na Europa capitalista, por pressão dos partidos operários, antes da Primeira Guerra Mundial já havia ocorrido uma tentativa de nacionalização dos setores industriais mais importantes. Nenhuma nacionalização, entretanto, foi efetuada na Alemanha, poucas foram registradas na Áustria, e na França foram nacionalizadas apenas algumas empresas produtoras de material de guerra que constituíram sociedades de economia mista na indústria da aeronáutica (Nunes, 2011).

Apenas com o fim da Segunda Guerra Mundial, e em consequência dela, é que se impuseram, desde logo, as nacionalizações e as intervenções do Estado na economia, por razões pragmáticas: "acreditava-se que a reconstrução só poderia ser levada a cabo por uma instância central que controlasse o aforro disponível e decidisse sobre a prioridade dos investimentos” (Nunes, 2011, p. 168). Como exemplo de nacionalização,

[...] a Inglaterra foi talvez o país que foi mais longe neste caminho. As despesas do estado inglês representaram, no exercício de 19421943 , cerca de $80 \%$ do rendimento nacional. O receio de que, perante as contingências do conflito, não fosse possível amortizar os capitais que investissem - apesar de serem em geral muito lucrativos os negócios e apesar de haver capitais disponíveis -, levava as empresas privadas a não investir em determinados setores. Embora as fábricas privadas já existentes não estivessem a utilizar toda a capacidade instalada, o governo americano foi, assim, obrigado a construir, com fundos públicos, fábricas que depois vieram a ser exploradas por aqueles que tinham recusado construí-las (Nunes, 2011, p. 167-168). 
O Estado passou, então, a ocupar uma posição importante no seio da economia. E nesse cenário de centralização e de nacionalização deu-se a Terceira Revolução Industrial - o aparecimento da energia nuclear, da automação, da eletrônica e da indústria espacial, enfim, o início de um período de intensa inovação científica e de rápida aplicação das novas conquistas da ciência. Um surto de nacionalização, por toda a Europa, que esteve na base da constituição de um setor empresarial do Estado relativamente significativo.

As nacionalizações atingiram, segundo Nunes (2011, p. 170), "um âmbito mais vasto e enquadraram-se em objetivos de transformação econômica e social.” Nos países que vieram a integrar a comunidade socialista, como Checoslováquia, Polônia e Iugoslávia, somente escaparam à nacionalização as pequenas e médias empresas. Também foi observado surto de nacionalização no Reino Unido e na França.

Muitos acreditaram que as nacionalizações na França e na Inglaterra podiam bem servir como primeiro degrau do socialismo, porém os países europeus que permaneceram na órbita capitalista mantiveram o setor privado de muitas empresas de grande dimensão. E como bem dispôs Nunes (2011, p. 171-172), nas palavras de Teixeira, “ou as nacionalizações prosseguem até eliminar do sector privado todas as grandes empresas, ou as grandes empresas hão-de ameaçar permanentemente a política do setor público.”

As perspectivas abertas com as nacionalizações, contudo, não conduziram claramente a utilização do setor público empresarial ao serviço de uma política global de desenvolvimento econômico e social com vista à satisfação das necessidades individuais e coletivas das populações, numa lógica não capitalista. Na verdade, elas não prosseguiram até eliminar do setor privado todas as grandes empresas, mantendo-se inalterada nesses países a natureza capitalista do Estado. 
Logo, a nacionalização traduziu-se em colocar o setor empresarial do Estado a serviço dos lucros privados, transformando a propriedade pública em uma nova forma de propriedade capitalista. Nesse sentido,

se as perspectivas abertas com as nacionalizações tivessem conduzido à utilização do setor público empresarial claramente ao serviço de uma política global de desenvolvimento econômico e social com vista à satisfação das necessidades individuais e coletivas das populações, numa lógica não capitalista, poderia esperar-se que este "estado social" viesse a abrir o caminho para uma economia não capitalista, "uma economia ao serviço do homem”. Mas a orientação adoptada traduziu-se em colocar o setor empresarial do estado ao serviço dos lucros privados, numa solução de capitalismo de estado, em que a propriedade pública se afirmou como uma nova forma de propriedade capitalista (Nunes, 2011, p. 172).

Diante desse quadro institucional, a propriedade estatal dos meios de produção assegurou uma nova forma jurídica da propriedade capitalista, a par da propriedade individual e da corporativa. E nesse contexto, no início da década de 50, o capitalismo se recuperou.

Com relação à expansão do capital estrangeiro no Brasil, esta remonta a muito antes das duas grandes guerras. A exemplo, o ciclo de expansão holandês, ocorrido desde o final do século 16 até 18, passando pelo ciclo britânico, com início no século 19 até meados do século 20, e continua se expandindo com a hegemonia norte-americana (Gonçalves, 1999).

Foi entre a Primeira e a Segunda Grande Guerra, entretanto, que se notou no Brasil uma presença significativa de capital estrangeiro. Empresas britânicas investiam nos moinhos e nas indústrias têxteis e calçadistas do país. O capital norte-americano era aplicado nas indústrias de alimentos, equipamento ferroviário, lâmpadas, transformadores, aparelhos domésticos, fonógrafos e sacos de papel. Empresas como Ford, General Motors e Chrysler instalaram suas primeiras unidades entre 1920 e 1930, 
propiciando o desenvolvimento da metalurgia, couro e vidro, até que em 1940 passaram a produzir todas as carrocerias de caminhões e ônibus. Por fim, entre a segunda e a terceira década do século 20, estabeleceram-se empresas como General Electric, Nestlé, Pirelli, entre outras tantas, fixando organizações de serviços e escritórios comerciais no país.

O Investimento Externo Direto (IED) acompanhou a referida industrialização, que se perpetrou durante as três primeiras décadas do século 20. O capital estrangeiro chegou a receber o mesmo tratamento em relação ao capital nacional, a exemplo de privilégios de taxas de retorno mínimo garantidas ou até mesmo empréstimos internos com taxas preferenciais e isenção fiscal, no entanto com as Constituições de 1934 e de 1937, influenciadas por fatores estratégicos militares teve início uma fase de restrições (Gonçalves, 1999).

A restrição ao capital estrangeiro, como bem lembra Nunes (2011, p. 148), já era adotada pela Constituição de Weimar (1919-1933), ao pregar “o princípio de que não pode confiar-se ao capital privado a gestão de determinados setores de produção, nomeadamente os que representam uma eminente utilidade social (a produção e distribuição de energia será, então, o exemplo mais relevante).” E complementa que a “nacionalização das empresas susceptíveis de socialização surge como um dos instrumentos utilizáveis para colocar sob a alçada do Estado aqueles bens econômicos de utilidade social e ainda as empresas que laboram em situação de monopólio."

Após o fim da Segunda Guerra Mundial as restrições foram eliminadas, tornando o Brasil, entre 1946 e 1962, um ambiente liberal para o capital estrangeiro. Ademais, com o golpe de Estado de 1964, houve por parte do governo um comprometimento com a economia capitalista, mediante a adoção de uma política liberal em relação ao capital estrangeiro. Assim, o pós-guerra foi caracterizado pelo salto na industrialização substitutiva de importações. A economia do Brasil teve um aumento de suas taxas de 
crescimento entre os anos de 1947 e 1961 - inclusive durante a profunda crise política e econômica, as produções agrícolas e industriais continuaram crescendo (Gonçalves, 1999).

Essa política explícita de industrialização, todavia, fez com que o governo adotasse controles cambiais - regime de câmbio fixo, ocorrendo uma queda das reservas internacionais em virtude da importação de bens de consumo duráveis. Além disso, o governo estabeleceu um controle cambial, num sistema de licenciamento que durou até 1953 - Lei do Similar Nacional -, no qual os produtos fabricados nacionalmente eram registrados no Conselho de Política Aduaneira e protegidos contra importações por meio de tarifas mais elevadas (Gonçalves, 1999).

Com o final da Segunda Guerra até 1961, o capital estrangeiro encontrou ambiente liberal no Brasil, contudo com ambivalências. Por exemplo, em 1953 houve restrições com relação à repatriação e à remessa de lucros, pois essas transferências poderiam ser feitas pelo mercado de câmbio livre. Tais investimentos externos foram insignificantes até 1954 devido à interação de fatores internos - baixo grau de industrialização, baixo nível de renda. Em 1955, com a Instrução $n^{0} 113^{1}$ da Sumoc, permitiu-se às empresas estrangeiras importarem bens de capital sem cobertura cambial, desde que o investidor aceitasse o valor do equipamento como participação de capital na empresa que fosse usar o bem.

Houve adesão de 80\% do IED, perdurando esses benefícios até 1961, quando foi alterada a política cambial. Além das referidas adições, a época propiciava um clima favorável para o investimento devido ao crescimento econômico gerado pelo Plano de Metas (Gonçalves, 1999).

${ }^{1}$ Essa instrução evitava que o investidor estrangeiro trouxesse investimento na forma de moeda estrangeira, convertesse em moeda nacional e usasse esta para comprar divisas para a importação de bens de capital. 
Na sequência, dispondo ainda sobre o investimento estrangeiro e nacional, veio a Lei $\mathrm{n}^{\circ} 4.390$, que alterou artigos da lei anterior. Esta foi regulamentada pelo Ato Executivo $\mathrm{n}^{\mathrm{0}}$ 55.762/65, em vigor até hoje, com pequenas alterações feitas nos anos 90 , pela Lei $\mathrm{n}^{0}$ 8.383/91 e pela reforma constitucional de 1995 (Gonçalves, 1999).

Mesmo assim, entre 1968 e 1973 o setor industrial foi a locomotiva da economia brasileira, com crescimento do segmento de bens de consumo duráveis. A partir de 1974 o mencionado segmento foi substituído por importações de insumos intermediários e bens de capital. Os investimentos estrangeiros corresponderam, até o final da década de 70, aproximadamente a um terço da produção industrial brasileira, em especial nas indústrias tecnológicas, as quais se tornaram oligopólios ou concorrência monopolística, sendo responsáveis por dois terços da produção nacional.

Nos anos 80 ocorreu um grande período de estagnação econômica, caracterizado pela geração de lucros e ao mesmo tempo de recuos de investimentos no país. Os anos 90 foram marcados pelo agravamento da crise, e, então, por uma reestruturação produtiva -racionalização de custos, redução da verticalização, demissões, abandono de algumas linhas de produção - das empresas de capital estrangeiro, adotando estratégias defensivas em relação a essa (Gonçalves, 1999).

Do ponto de vista geral, a entrada de capital estrangeiro foi interpretada pelos governos como um indicador de confiança dos agentes internacionais acerca da política de governo local. De acordo com Gonçalves (1999), porém, tais perspectivas trouxeram sérios problemas como o agravamento das contas externas, baixo desempenho da economia brasileira e o financiamento das contas públicas por meio das privatizações das empresas públicas e das concessões. Logo, ao invés de ocasionar uma arrecadação de recursos junto aos investidores estrangeiros e uma diminuição dos encargos da dívida interna do governo central, houve o aumento da dívida. 
Em suma, no decorrer dos anos, o Brasil viveu e vive um paradoxo em relação aos capitais estrangeiros: de um lado a geração de lucros, e de outro o recuo dos investimentos no país.

\section{OS FUNDAMENTOS DEMOCRÁTICOS PÓS-SEGUNDA GUERRA MUNDIAL: entre regulação econômica e democracia}

No regime liberal, ao Estado competia, basicamente, a função de produção do Direito, ou seja, o provimento da justiça e da segurança. Os homens tinham o direito de contratar livremente, de acordo com sua vontade, e o Estado não podia interferir na "ordem natural” da economia, exceto quando houvesse interesse no capital e no desenvolvimento de ideias capitalistas baseadas em um mercado livre. Essa não intervenção do Estado na economia foi uma opção adotada em prol do desenvolvimento econômico, da livre concorrência e em favor do predomínio das leis de mercado.

Devido às imperfeições do liberalismo, associadas à incapacidade de autorregulação dos mercados, necessária se fez uma remodelação do papel do Estado diante dos interesses de mercado. $\mathrm{O}$ fator decisivo para tanto deu-se em 1929, com a queda da Bolsa de Nova York e o início da chamada Grande Depressão. O Estado foi forçado a retomar a responsabilidade pela movimentação da economia, controlar a moeda e o crédito, amplamente abalados pela depressão, aplicar uma política tributária baixa, sem deixar de prover a justiça e a segurança. Inicia-se, então, uma nova fase: o Estado como regulador do poder econômico.

A fase intervencionista visava a propiciar à sociedade adquirir ganhos e rendimentos e assim movimentar a economia. O Estado passou a ser o idealizador e realizador das políticas econômicas e sociais, retomando a nacionalização da economia, por meio da criação dos monopólios 
estatais. Forma-se o Estado de Bem-Estar Social (Welfare State), caracterizado pelo gerenciamento da economia e práticas de políticas sociais direcionadas ao bem-estar dos cidadãos.

Observa-se, assim, que o capitalismo liberal foi substituído pela intervenção de um Estado regulador da economia, da emissão de moeda, e, ainda, do poder de polícia e dos serviços públicos. A “extensão de suas funções manifesta-se como exigência do processo de acumulação de capital, redobrada quando a realização do desenvolvimento é erigida à condição de ideal social” (Grau, 2002, p. 21).

Ademais, o Estado foi convocado a suprir as insuficiências de um sistema em que de um lado a "força de trabalho/mercadoria é o único bem que constitui propriedade de largas parcelas da população e, por outro, era imperiosa a necessidade de formação de poupanças para a reprodução do capital” (Grau, 2002, p. 21). Nesse clima, germina a ampliação do Estado-aparato e do Estado-ordenamento e se reconsagra a vocação do Direito para a defesa da propriedade, bem como é selada uma aliança entre o setor privado/burguesia e o setor público/a serviço da burguesia, com o objetivo de buscar o desenvolvimento.

O Estado, ao atuar como agente de instituição de políticas públicas, enriquece suas funções de integração, de modernização e de legitimação capitalista, entretanto, embora seja chamado para atuar sobre e no domínio econômico, isso não conduz à substituição do sistema capitalista por outro. Ao contrário, é justamente para impedir tal substituição que o Estado é chamado a atuar. Assim, o sistema capitalista é preservado, havendo a manutenção do pleno poder das classes dominantes, promovendo a fragmentação social. A esse capitalismo modernizado dá-se o nome de progressista (Grau, 2002).

A partir dos anos 70, após a crise do petróleo, começou a ser questionado o papel do Estado por meio de discursos de desregulação. Surge uma nova fase: o neoliberalismo, caracterizado pelo combate à política 
intervencionista do Estado de Bem-Estar Social, mediante uma política intervencionista mínima no que tange aos direitos sociais e trabalhistas. O Estado tornou-se agente passivo em relação à lei de mercado e ao lucro capitalista.

Mundialmente, o neoliberalismo ganhou terreno a partir dos governos Thatcher e Reagan. Com a globalização surgiram as empresas multinacionais e a modernização tecnológica dos meios de produção e telecomunicação. Isso ocasionou o enfraquecimento do Estado de Bem-Estar Social, com a desestatização da economia, o aumento das privatizações, das concessões, das permissões dos serviços públicos, e, simultaneamente, as supressões dos direitos trabalhistas (flexibilização).

Nas palavras de Perry Anderson citado por Grau (2002, p.38), economicamente, o neoliberalismo fracassou, não conseguindo nenhuma revitalização básica do capitalismo avançado. Socialmente, ao contrário, o neoliberalismo conseguiu muitos dos seus objetivos, criando sociedades marcadamente mais desiguais, embora não tão desestatizadas como queria. Política e ideologicamente, todavia, o neoliberalismo alcançou êxito num grau com o qual seus fundadores provavelmente jamais sonharam, disseminando a simples idéia de que não há alternativas para os seus princípios, que todos, seja confessando ou negando, têm de adaptar-se a suas normas.

O fato é que a ideologia de mercado é produzida em razão dos interesses do investidor, ou seja, de baixar os custos que oneram a empresa, tais como salários, tributos e encargos sociais. Assim, como bem expõe Grau (2002, p. 39), “o capitalismo é essencialmente conformado pela microrracionalidade da empresa, não pela macrorracionalidade reclamada pela sociedade.”

Corroborando, Ferrajoli (2007) entende que com a intervenção internacional ocorre o enfraquecimento do Estado e, automaticamente, da autossuficiência e da exclusividade normativa no plano jurídico, da 
soberania no plano político e da centralização no plano econômico. Tem-se a estagnação do Estado diante dessa força capitalista global: o domínio econômico se confirma no sistema capitalista, com a manutenção do poder pela classe dominante e a segregação das classes sociais.

Nas palavras de Bauman (2001), é escassa a possibilidade de se resgatarem os serviços, a segurança e as garantias do Estado em razão da liberdade política dos novos poderes globais. O jogo da dominação formado na era da modernidade líquida não é mais jogado entre o maior e o menor, mas entre o mais rápido e o mais lento. Dominam os que são capazes de acelerar além da velocidade de seus opositores. O poderio da elite global está na capacidade de escapar aos compromissos locais, bem como a globalização destina-se a evitar essa necessidade, a conferir ao Estado tão somente a missão de guardião da lei e da ordem.

Para as multinacionais ou empresas globais com interesses e compromissos locais dispersos e cambiantes, o mundo ideal é um mundo sem Estados, ou pelo menos com pequenos e não grandes Estados, pois quanto menor, mais fraco. Nesse sentido, Bauman (2001, p. 219) dispõe que

o que temos hoje é, com efeito, um sistema dual, o sistema oficial das economias nacionais dos Estados, e o real, mas não oficial, das unidades e instituições transnacionais. Ao contrário do Estado com seu território e poder, outros elementos da nação podem ser e são facilmente ultrapassados pela globalização da economia. Etnicidade e língua são dois exemplos óbvios. Sem o poder e a força coercitiva do Estado, sua relativa insignificação é clara.

Ou seja, para Bauman (2001) a soberania do Estado-nação estava desacreditada e removida dos estatutos do Direito Internacional em consequência da sua incapacidade de resistência e da substituição do mundo das nações pela ordem supranacional. Tal fato propiciou uma política de precarização, isto é, um golpe na soberania e a perda do monopólio de coerção. 
Ferrajoli (2007), ao tratar da crise de soberania do Estado, entende que, em razão da transferência do Direito Interno dos Estados para o Direito Internacional, alteraram-se as figuras da soberania, da cidadania e os vínculos normativos da paz e dos direitos fundamentais do nacional para o supranacional. A ideia de cidadania intimamente ligada com a percepção nacional como pressuposto de direito abriu precedente a uma cidadania universal dos direitos fundamentais, isto é, de prevalência dos ordenamentos internacionais, de universalismo.

Nesse contexto de neoliberalismo, é importante destacar que o Brasil foi e é uma sociedade registrada por políticas de apropriação da esfera pública em virtude dos interesses particulares de grupos poderosos, o que a faz hierarquizada. Segundo Carvalho (2001), ao contrário dos países europeus, no Brasil a cidadania não se constituiu historicamente, vez que as relações de favor, de dependência, atravessaram a formação política brasileira. As classes dominantes do país acostumaram-se a fazer do Estado brasileiro seu instrumento econômico privado por excelência. Logo, diante da realidade brasileira em que se faz do interesse privado a medida de todas as coisas, obstruindo a esfera pública, anulando a dimensão ética da vida social pela recusa das responsabilidades e obrigações do Estado, inviável o discurso neoliberal.

Do todo, tem-se que o fenômeno da globalização interferiu de forma significativa e universal nos sistemas produtivo e financeiro ao enfraquecer o poder de controle e intervenção do Estado sobre fluxos internacionais. Ademais, ao afetar a economia e as relações políticas dos Estados, território e população, impôs uma revisão dos conceitos de política, democracia e Estado conforme o processo de integração instaurado nos diversos espaços. A globalização, ao mesmo tempo em que cria demandas, cria também novas possibilidades para a regeneração de identidades locais. 


\section{GLOBALIZAÇÃO: economia, direito e democracia}

A globalização é um processo típico da segunda metade do século 20 e conduz à crescente integração econômica, política e social dos vários países. Trata-se da internacionalização de produtos, serviços, mercados financeiros, pessoas e informações, mediante contribuição das novas tecnologias de comunicação e de processamento de dados.

Segundo Eros Grau (2002, p. 45), não há uma relação necessária entre globalização e neoliberalismo. Ele defende que “a 'globalização' é um fato histórico; o neoliberalismo, uma ideologia. A 'globalização' decorre da terceira Revolução Industrial - informática, microeletrônica e telecomunicações -, realizando-se como 'globalização financeira'.” Dessa forma, pode a globalização conviver com outras ideologias, desde que em condições político-sociais passíveis de viabilizar a concepção de uma sociedade socialista globalizada.

Um fato incontestável, porém, é que a globalização abalou as bases da cidadania tradicional, uma vez que enfraqueceu os laços territoriais que ligam o indivíduo e os povos ao Estado, deslocando o foco da identidade política, diminuindo a importância das fronteiras internacionais. Nesse sentido Pena (2012) observa que

tudo indica que a construção do futuro tende a transformar a cidadania nacional, surgida com os Estados territoriais modernos, em forças sociais transnacionais, abrindo caminho para a criação de uma sociedade civil global emergente. A idéia de que a cidadania global teria apenas uma força moral é originária da Paz Perpétua de Kant, com o seu apelo à solidariedade em relação aos estrangeiros.

As dificuldades encontradas para o estabelecimento de uma democracia que amplie a cidadania e os constantes desafios políticos, econômicos e sociais impostos pelos ajustes promovidos pelas políticas neoliberais demandaram, sem dúvida, um esforço de reflexão. 
De acordo com Ferrajoli (2007), a crise e a deformação da democracia e do Estado de Direito são geradas por um vazio do Direito Público, característico do processo de globalização sem regras, e se manifesta com a diminuição dos poderes e das funções públicas reservadas ao Estado. O futuro de um país depende cada vez menos da política interna e cada vez mais de decisões externas, adotadas por meio de políticas extras, supraestatais e de poderes econômicos e financeiros globais.

Na mesma linha, Eros Grau (2002, p. 40) entende ser difícil harmonizar o crescimento econômico, a sociedade civil e a liberdade econômica no clima do mercado global. Na sua visão, a globalização ameaça a sociedade civil, na medida em que

i) está associada a novos tipos de exclusão social, gerando um subproletariado (underclass), em parte constituído por marginalizados em função da raça, nacionalidade, religião ou outro sinal distintivo; ii) instala uma contínua e crescente competição entre os indivíduos; iii) conduz à destruição do serviço público (= destruição do espaço público e declínio dos valores do serviço por ele veiculados). Enfim, a globalização, na fusão de competição e de desintegração social, compromete a liberdade.

Segundo Faria (2012), o avanço do fenômeno está aprofundando a desigualdade e a exclusão, visto que os ganhos de produtividade têm sido obtidos, em grande parte, por meio da degradação salarial, da informatização da produção e do subsequente fechamento dos postos de trabalho convencional. A simbiose entre marginalidade econômica e marginalidade social obriga as instituições jurídicas do Estado-nação a concentrarem sua atuação na preservação da ordem, da segurança e da disciplina.

Nesse diapasão o primeiro-ministro francês, Lionel Jospin (1997/2002), bem lembrado por Eros Grau (2002), alerta que para haver o bom funcionamento de uma economia de mercado são necessárias 
novas regras estáveis e passíveis de reforçar as legislações dos Estados ao mesmo tempo em que conduzem a um novo universalismo, aquele dos direitos humanos. Ou seja,

as forças econômicas que se manifestam na economia globalizada devem ser orientadas, o que exige governos responsáveis, determinados a agir com voluntarismo, instituições multilaterais legítimas e transparentes que respeitem os direitos de todos os Estados. Assim a comunidade internacional poderá organizar a mundialização segundo e conforme o Direito e a Justiça (Grau, 2002, p. 46).

$O$ fato é que a globalização criou uma nova realidade alheia às fronteiras físicas ou geográficas para o mercado capitalista, determinando, dessa forma, mudanças nas relações políticas e sociais entre os Estados. No entendimento de Cabral (2012), houve, na esfera da política, uma universalização de valores, por exemplo, de democracia, direitos humanos e preservação ambiental, restando comprovada a importância da instituição de um regime internacional. Há interesses e objetivos comuns dos povos e Estados e reflexos sobre as respectivas instituições nacionais.

Na mesma linha, Ferrajoli (2007) justifica a crise do Estado no plano internacional na falta de regras, limites e vínculos em garantia da paz e de direitos humanos ante os novos poderes transnacionais, tanto públicos quanto privados. Esse novo paradigma do mundo contemporâneo coloca em contato os atores sociais e os eventos econômicos, políticos, culturais e comunicativos.

Essa ausência de regras do atual capitalismo globalizado, no entanto, é a nova ordem econômica mundial, marcada pelos fenômenos conexos e convergentes: crise de soberania do Estado, crise da democracia nacional e globalização. Em conjunto, seus efeitos, no entendimento de Ferrajoli (2007), são um “neoabsolutismo” global, ou seja, desenvolvimento dos poderes econômicos e políticos, contraditórios e confusos, e 
deslocamento dos poderes da esfera pública para o mercado e as instituições extraestatais diretas e indiretas controladas pelas grandes empresas privadas.

Os novos poderes extras ou supraestatais obrigam a repensar a esfera pública, esta cada vez menos à altura de garantir a paz e os direitos fundamentais. O aumento do desemprego, por exemplo, foi reflexo da execução das políticas neoliberais, distinta pela expansão dos mercados financeiros e enfraquecimento do Estado.

A economia capitalista neoliberal representa, além de alto número de desempregados, o aumento da insegurança e da exclusão social, taxas de crescimento desanimadoras e reduzidas taxas de investimentos empresariais. Apenas os mercados financeiros prosperam, em razão dos efeitos da desregulamentação. Consoante Eros Grau (2002), em razão da crise que vem afetando os mercados de todo o mundo nos últimos anos, estaria ocorrendo o declínio do neoliberalismo.

O Estado-nação, na concepção de Faria (2012), encontra-se em um impasse: de um lado, não consegue mais disciplinar e regular a sociedade e a economia exclusivamente por meio de seus instrumentos jurídicos tradicionais; por outro, não assegura a eficaz regulação direta e centralizadora das situações sociais e econômicas. A globalização traz uma nova conjuntura que abrange não somente a economia, mas também as relações políticas dos Estados, tanto externa quanto internamente.

O fenômeno exige uma revisão dos conceitos de política, democracia e Estado, em razão do processo de integração instaurado nos diversos espaços. Nas lições de Cabral (2012), necessária a universalização de alguns valores, o que gera um custo social e político muito elevado, na medida em que interfere no ordenamento jurídico dos Estados, modificando os contornos de sua soberania, criando níveis diferenciados entre aqueles menos desenvolvidos economicamente. 
Eros Grau (2002), diante da oposição entre o neoliberalismo, o qual exclui e marginaliza, e a democracia, que supõe o acesso de um número cada vez maior de cidadãos aos bens sociais, igualmente entende imperioso reestruturar ideias. O discurso liberal, viabilizador do acesso dos homens a direitos e garantias sociais e individuais, é confrontado pelo discurso neoliberal, repressor dessas liberdades formais. "Daí por que o neoliberalismo é autofágico: ao investir contra esses direitos, fere profundamente o próprio sistema” (Grau, 2002, p. 48).

A democracia, neste mundo globalizado, precisa ser visualizada e pregada, como bem expõe Maria Benevides (1996), como um "regime político fundado na soberania popular e no respeito integral aos direitos humanos," definição esta que tem a vantagem de agregar democracia política e democracia social e assim reunir

os pilares da "democracia dos antigos" - tão bem explicitada por Benjamin Constant e Hannah Arendt, como a liberdade para a participação na vida pública - aos valores do liberalismo e da democracia moderna, quais sejam, as liberdades civis, a igualdade e a solidariedade, a alternância e a transparência nos poder (contra os arcana imperi de que fala Bobbio), o respeito à diversidade e a tolerância.

Quanto ao Brasil nesse contexto de redefinições, sintetiza Maria Benevides (1996) que

durante o regime militar (1964-1985) o Brasil viveu um período de redução dos direitos de cidadania e de minimização da atividade política. Isso correspondeu a uma concepção economicista/produtivista da sociedade, na qual a única função meritória dos indivíduos é produzir, distribuir e consumir bens e serviços. Com o movimento de democratização do país e com o reconhecimento universal de que não há desenvolvimento exclusivamente no campo econômico, sem concomitante desenvolvimento social e político, a questão da educação política se tornou de fundamental importância. Hoje podemos afirmar que a cidadania é uma idéia em expansão; no entanto, a ação política continua 
desvalorizada e o cidadão pode ser visto apenas como o contribuinte, $o$ consumidor, o reivindicador de benefícios individuais ou corporativos, e não do bem comum.

Certo é que a sociedade globalizada não se satisfaz mais apenas com o governo da maioria, e sim, requer a possibilidade de desenvolver, em todos os seus membros, a capacidade de pensar, participar na elaboração e aplicação das políticas públicas e julgar os resultados. Em especial porque o conhecimento dos direitos não é suficiente para que eles sejam respeitados, promovidos e protegidos. Segundo Maria Benevides (1996), "é preciso entendê-los nas suas origens, mas também no seu significado atual e universal, assim como é mister compreender as dificuldades políticas e culturais para sua plena realização.”

É preciso repensar alternativas de resistência ou de enfrentamento das dinâmicas individualistas e mercantilizadas típicas aos diagnósticos do presente. E, apesar de conhecidos os bons e importantes reflexos de uma democracia política e social, de uma cidadania ativa, permanece uma soberania compulsoriamente partilhada do Estado, o qual acaba se sujeitando, sob pena de ficar à margem dessa economia globalizada.

\section{CONSIDERAÇÕES FINAIS}

Uma nova ordem econômica nasceu com a Segunda Guerra Mundial e em virtude do fenômeno da globalização. As dimensões financeira, produtivo-real, comercial e tecnológica foram afetadas. Houve expansão do fluxo internacional de bens, serviços e capitais, acirramento da concorrência nos mercados internacionais e integração dos sistemas econômicos nacionais.

O Estado, que até então ocupava uma posição importante no terreno da economia, com sua política de nacionalização, deixou de corresponder às expectativas. Não conseguiu conduzir a utilização do setor 
público empresarial ao serviço de uma política global de desenvolvimento econômico e social, com vista à satisfação das necessidades individuais e coletivas das populações, numa lógica não capitalista.

A política liberal, marcada pela presença do capital estrangeiro e não intervenção estatal, propiciou um salto na industrialização e, em consequência, na economia. Ao Estado coube, basicamente, o provimento da Justiça, com o desenvolvimento econômico sendo gerido pela livre-concorrência e leis de mercado.

Em razão da incapacidade de autorregulação dos mercados, porém, a qual teve o apogeu em 1929, com a queda da Bolsa de Nova York, necessário fez-se uma remodelação do papel do Estado, o qual foi compelido a retomar a responsabilidade pela movimentação da economia, sem deixar de prover a Justiça e a segurança, bem como sem conduzir a uma substituição do sistema capitalista por outro.

$\mathrm{Na}$ década de 70, diante da crise do petróleo, ocorreu um movimento pela desregulação, que culminou no neoliberalismo e na retomada do capitalismo livre das amarras impostas pelo Estado-intervencionista. Dessa vez, no entanto, houve considerável limitação da soberania do Estado, ao abrir espaço para uma internacionalização das relações tanto políticas quanto econômicas, e um novo entendimento de democracia, não mais voltada ao Estado-nação, mas sim em escala interdependente entre nações.

Essa interferência da globalização nos sistemas produtivo e financeiro e no poder de controle e intervenção do Estado sobre fluxos internacionais, afetando a economia e as relações políticas dos Estados, território e população, demanda uma revisão dos conceitos de política, de democracia e de Estado. Ademais, também requer uma alternativa de caráter normativo quanto à regulação do mercado global e à constituição de uma esfera pública transnacional. 
A ausência de regras do atual capitalismo globalizado reflete a nova ordem econômica mundial: crise da soberania do Estado e da democracia nacional. Esta, por sua vez, clama por formas alternativas de resistência ou de enfrentamento das dinâmicas individualistas e mercantilizadas típicas dos diagnósticos do presente.

Ao agregar a democracia política à social é possível substituir a cidadania passiva, fruto do capitalismo, por uma cidadania ativa e participativa, de cidadão portador de direitos e deveres. Essa nova visão de democracia, se colocada em prática, pode ajudar a reverter o predomínio do individualismo em detrimento do cidadão, com a sucumbência do interesse público pelo privado, do enfraquecimento do Estado em virtude dos fluxos internacionais.

\section{REFERÊNCIAS}

BAUMAN, Zygmunt. Modernidade líquida. Rio de Janeiro: Zahar, 2001.

BEDIN, Gilmar Antonio. A sociedade internacional clássica - aspectos históricos e teóricos. Ijuí: Ed. Unijuí, 2011.

BENEVIDES, Maria Victoria. Educação para a democracia: versão resumida de conferência proferida no âmbito do concurso para professor titular em sociologia da educação na Feusp, 1996. Disponível em: <http://www.hottopos. com/notand2/educacao_para_a_democracia. htm>. Acesso em: mar. 2013.

CABRAL, Lucíola Maria de Aquino. Globalização e democracia: os direitos sociais no cenário político brasileiro. Disponível em: $<$ http://luciolacabral. wordpress.com/globalizacao-e-democracia/>. Acesso em: 8 jun. 2012.

CARVALHO, José Murilo de. Cidadania no Brasil. O longo caminho. Rio de Janeiro: Civilização Brasileira, 2001.

COMPARATO, Fábio Konder. A afirmação histórica dos direitos humanos. 7. ed. São Paulo: Saraiva, 2011. 
FARIA, José Eduardo. Direitos humanos e globalização econômica: notas para uma discussão. Disponível em: <http://www.scielo.br/scielo.php?script=sci_ arttext\&pid=S0103-40141997000200004>. Acesso em: 8 jun. 2012.

FERRAJOLI, Luigi. Principia Iuris. Teoria del diritto e della democrazia. 2. Teoria del Diritto. Roma-Bari: Laterza, 2007.

GONÇALVES, Reinaldo. Globalização e desnacionalização. São Paulo: Paz e Terra, 1999.

GRAU, Eros Roberto. A ordem econômica na Constituição de 1988.7 ed. rev. e atual. São Paulo: Malheiros, 2002.

NUNES, Antonio Jose Avelãs. Aventuras e desventuras do Estado Social. In: Revista da Fundação Brasileira de Direito Econômico, vol. 3, n. 1, p. 141-223, 2011.

PENA, Fernando Marques. Democracia, direitos humanos e globalização. Disponível em: <http://www.espacoacademico.com.br/064/64pena.htm>. Acesso em: 8 jun. 2012.

Recebido em: 11/11/2013

Aceito em: 7/4/2014 